\title{
GEOLOGIC MAP OF THE HEART BUTTE NW QUADRANGLE, MORTON AND GRANT COUNTIES, NORTH DAKOTA \\ By \\ E. Vernon Stephens
}

COAL INVESTIGATIONS

MAP C-52

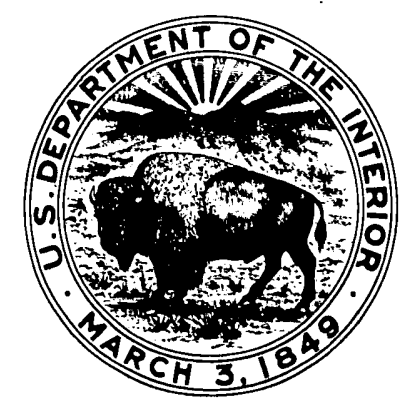

PUBLISHED BY THE U. S. GEOLOGICAL SURVEY

WASHINGTON, D.C. 